\title{
Long-Term Foster Care-Different Needs, Different Outcomes
}

WENDY A. WALSH AND MARYBETH J. MATTINGLY

1 pproximately 424,000 U.S. children have been removed from their regular home and are in substitute care by child protective services in a given year. ${ }^{1} \mathrm{~A}$ number of studies indicate children in foster care have higher rates of emotional and behavioral problems, about 30 percent, compared to children in the general population (about 4 percent). ${ }^{2}$ Children in foster care are sixteen times more likely to receive psychiatric diagnoses and eight times more likely than their peers to take psychotropic medications. ${ }^{3}$ Given these concerns, the American Academy of Pediatrics and the Child Welfare League of America recommends that children and teens in foster care are screened early and often to assess for mental health problems. ${ }^{4}$

This brief examines where children are living four years after removal from their homes and the characteristics of children and their placements. Understanding whether child characteristics such as age or emotional or behavioral problems are associated with a longer stay in out-of-home care can help identify children who are least likely to find permanence and may benefit from specialized services.

We analyzed data from a nationally representative sample of children placed in out-of-home care between July 1998 and February 1999. We find that after one year, 78 percent were still in out-of-home care. Only 15 percent of children were reunified with their parents, and 7 percent were adopted (see Figure 1).

Four years after removal, 43 percent of children were in out-of-home care (including 22 percent in foster care, 13 percent in kinship care, and 8 percent in a residential program, group home, or other living arrangement). Although children may have lived elsewhere during intervening years, four years after removal, only 28 percent were reunified with their parents and 29 percent were adopted.

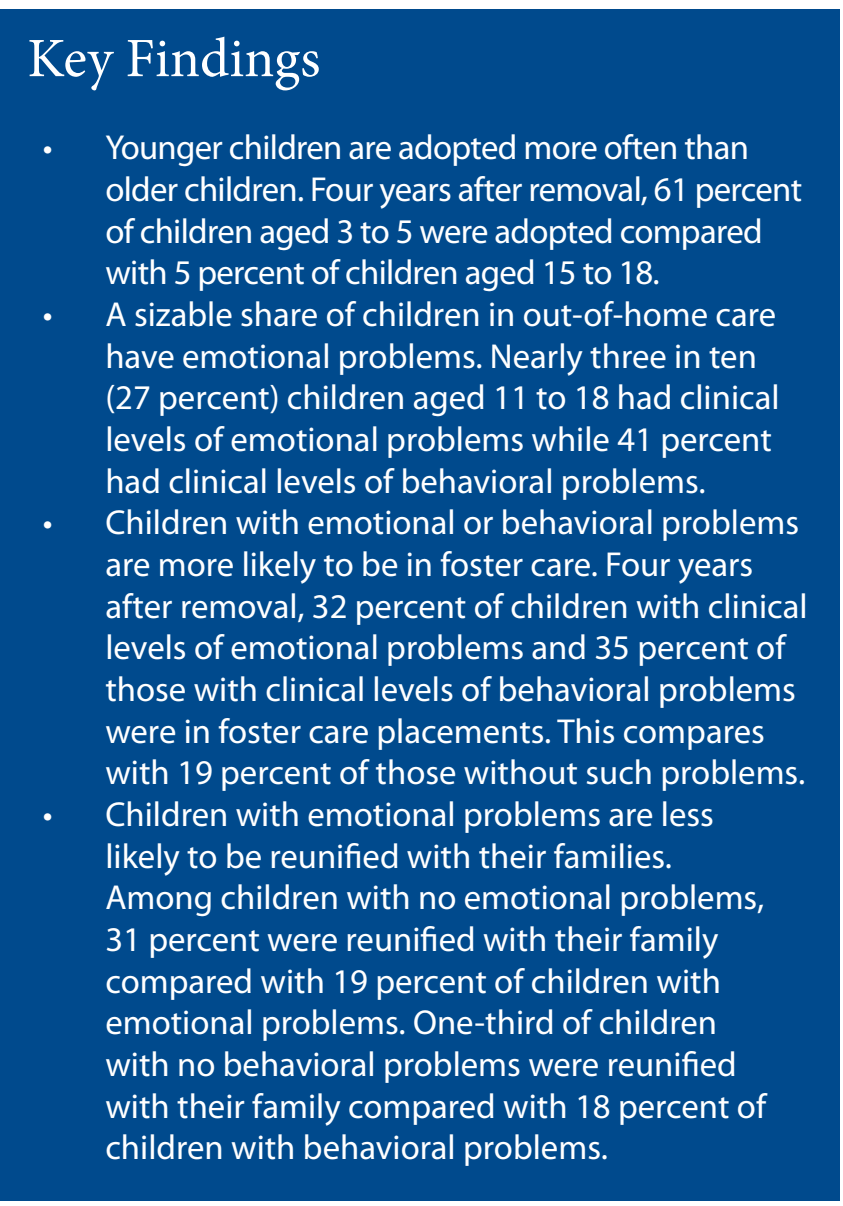

UNIVERSITY of NEW HAMPSHIRE 


\section{Figure 1. Placement OVer time}

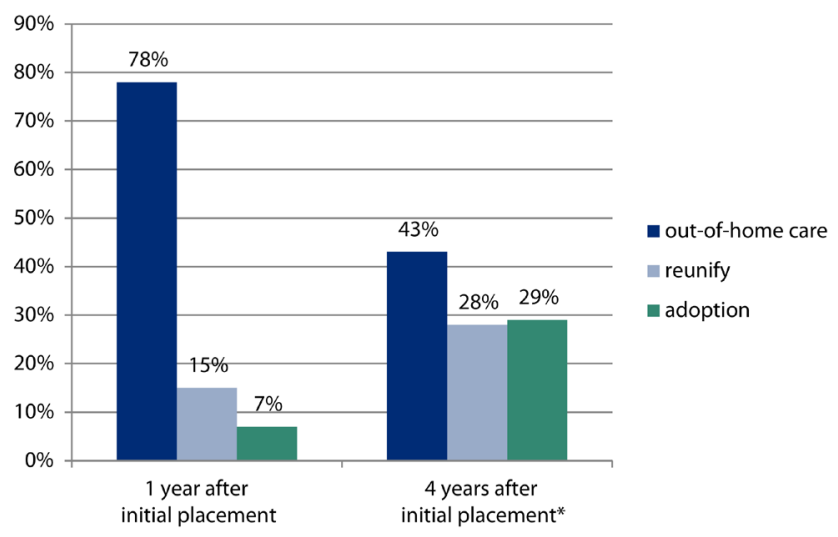

* Includes only children who were still in out-of-home care after one year. Children may have lived elsewhere during intervening years.

\section{Children's Age and Longer Term Out-of-Home Placement}

Age is often correlated with placement (see Figure 2). The adoption rate is much lower for older children, for example. Four years after initial removal, the majority (61 percent) of children aged 3 to 5 were adopted, but just over 20 percent of those aged 6 to 10 and 11 to 14 were, and only 5 percent of those over age 14 were adopted.

Age also comes into play in reunification rates. Four years after initial removal, children aged 6 to 10 were most often reunified with their families (39 percent), followed by children aged 15 to 18 (32 percent).

Four years after entry into out-of-home placement, more than half of the 15- to 18-year-olds (62 percent) and 11- to 14 -year-olds ( 55 percent) were living in foster care, kin care, or group homes, while fewer than one-quarter of the children aged 5 or younger were in such arrangements. There were no gender or race differences in placements.

Figure 2. Child AGE AND PLACEMENT FOUR YEARS AFTER PLACEMENT IN FOSTER CARE

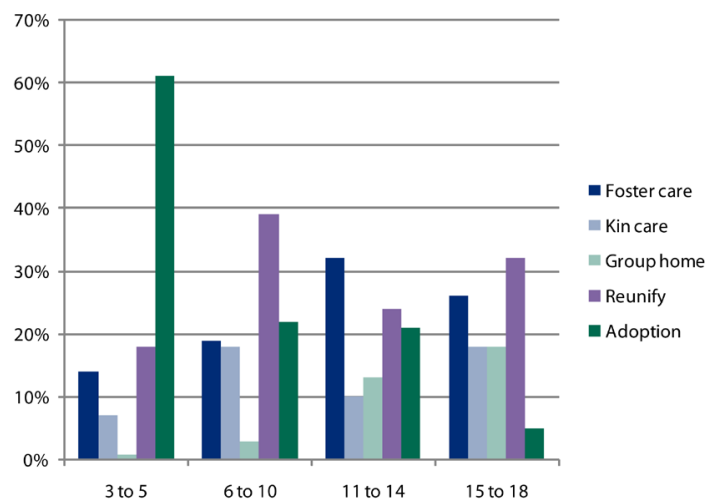

\section{Emotional and Behavioral Problems for Children in Foster Care}

In our study, rates of emotional problems did not differ significantly across the four age groups, but a smaller share of younger children had problems than older children (see Table 1). For example, 27 percent of children aged 11 to 18 had clinical levels of emotional problems compared with 10 percent of children aged 3 to 5 . Similarly, younger children had lower rates of behavioral problems compared with older children, but this difference was not statistically significant. For example, 41 percent of children aged 11 to 18 had clinical levels of behavioral problems compared with 19 percent of children aged 3 to 5 .

TABLE 1. EMOTIONAL AND BEHAVIORAL Problems and Child Age

\begin{tabular}{|l|c|c|}
\hline & Emotional Problems & Behavioral Problems \\
\hline 3 to 5 years & $10 \%$ & $19 \%$ \\
\hline 6 to 10 years & $19 \%$ & $25 \%$ \\
\hline 11 to 14 years & $27 \%$ & $43 \%$ \\
\hline 15 to 18 years & $26 \%$ & $38 \%$ \\
\hline
\end{tabular}

As for outcomes for these youth, we find that four years after placement, a higher share (32 percent) of children with emotional problems were in foster care than those with no emotional problems, and a lower share ( 9 percent) were in kinship care (see Figure 3). Kinship care is often a preferred arrangement as it is care by a relative and often less traumatic for children. Children with emotional problems also had much higher rates of placement in group homes (16 percent versus only 5 percent of those without emotional problems). Two-thirds of children with no emotional problems were either reunified (31 percent) or adopted (31 percent).

Figure 3. EMOTIONAL PROBLEMS AND PLACEMENT

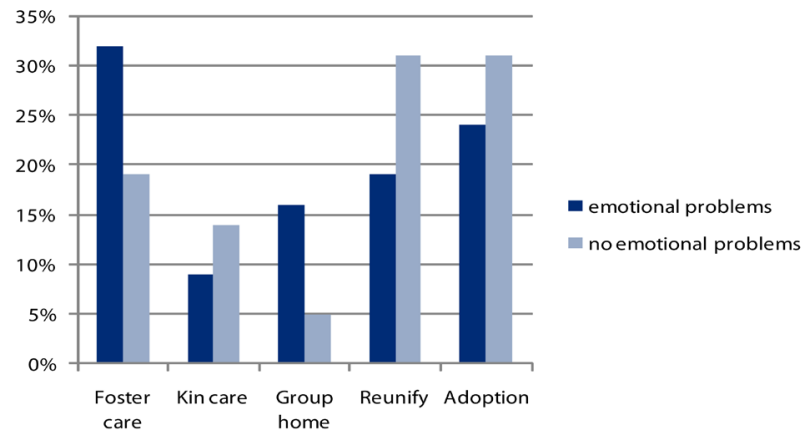


For children with behavioral problems, the patterns four years after placement were similar to those with emotional problems. Thirty-five percent were in foster care while only 11 percent were in kinship care (see Figure 4). They also had higher rates of placement in group homes, and had lower rates of reunification. Two-thirds of children without behavioral problems were either reunified or adopted four years later compared with 39 percent of those with behavioral problems.

\section{Figure 4. BehaVioral PROBlems AND PlaCEMENT}

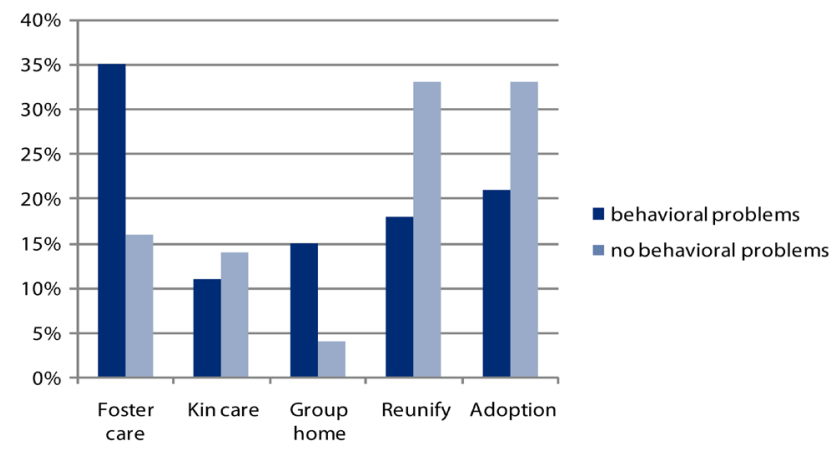

\section{Consequences of Long-Term Foster Care}

Children in long term foster care suffer from behavioral and emotional problems at alarming rates. Better identifying and assisting children with, or at risk of developing such problems upon entry to foster care and throughout their out-ofhome placement, may alleviate their needs and troubles and provide mechanisms for supporting them as they get older.

Differences in the likelihood of remaining in foster care point to important strategies for aiding these vulnerable children. That four years after initial removal 44 percent of youth aged 15 to 18 are in foster care or group homes (and thus not adopted, reunified, or with kin) underscores the importance of strategies to help these children in the transition to adulthood. In many states, foster care ceases at age 18 and the youth are on their own. Yet they are aging out of foster care at a time in life when many peers still require substantial guidance, structure, and support.

In addition, that so many of those with emotional and behavioral problems remain in foster care points to the importance of comprehensive mental health services for these young people. As children in foster care age, lack of recognition of the need for adequate mental health treatment may lead to further psychopathology. The Jim Casey Youth Opportunities Initiative has identified some of the major issues that youth confront as they age out of foster care, including meeting basic needs as they face barriers to completing their education, securing housing, and accessing medical care.

\section{Definitions}

Out-of-home placement is a substitute care arrangement with foster care, kinship care, group homes, emergency shelters, residential programs, and pre-adoptive homes. $^{5}$

Child behavior and emotional problems were measured using the Child Behavior Checklist (CBCL), which is completed by the current caregiver. A score of 64 or higher indicates the problems are clinical. Behavior and emotional problems were reported four years after initial placement.

Report of maltreatment is what child protective services uses to record suspected maltreatment.

Age of child refers to age at four years after initial placement.

Many who have aged out have low educational attainment, experience homelessness, and are less likely than age group peers to be working. Males who aged out of foster care were six times as likely as their peers to be convicted of a crime. ${ }^{6}$

A number of policies and programs address these issues by providing longer-term support and guidance during a transition period and assist former foster care youth in obtaining education, health insurance, and housing. An example is the Guardian Scholars Program at California State University, which covers full tuition, textbooks, supplies, and annual fees for former foster care youth. ${ }^{7}$ Assistance also includes year round on-campus housing and employment, counseling, and postgraduate career planning. The success of these programs is a call for more state and federal investment in the population that will continue to age out of foster care. In 2008, President George W. Bush signed "The Fostering Connections to Success and Increasing Adoptions Act of 2008," ${ }^{8}$ which promotes kin and relative care, and among other things allows states reimbursement for providing foster care for eligible ${ }^{9}$ youth up to age $21 .{ }^{10}$ States are not required to adopt the latter piece of this legislation, and as of April 2011, only eleven states had chosen to do so. ${ }^{11}$ While the policy is still relatively new, research shows that "the financial benefits of extending foster care-both for individual youth and for society-outweigh costs to government by a factor of approximately 2 to $1 .{ }^{\prime 12}$ These findings suggest that it may be worthwhile for states to reconsider their policies for the sake of long-term success. This type of investment may be significantly less expensive than the costs of the increased burdens on the community in the form of lost potential and would be a positive investment in these young adults. 


\section{Data}

Data for this brief come from the long-term foster care (LTFC) sample of the National Survey of Child and Adolescent Well-Being (NSCAW). The LTFC sample included 727 children who had been in out-of-home care for approximately one year at the time of sampling and whose placement had been preceded by an investigation of child abuse and neglect. Eligible children were randomly sampled from children placed into care between July 1998 and February 1999. NSCAW used a stratified two-stage cluster sampling strategy. Additional information on the NSCAW study design and sampling procedure has been previously published. ${ }^{13}$ The sample for the current analysis included 567 children who remained in out-of-home care during the initial wave of data collection. We examine outcomes four years after initial placement. Some children placed out of the home four years after initial placement may have been reunified at some point during the intervening years. Statistics were computed using survey weights to produce national estimates. All differences except where noted in the text are statistically significant at the 95 percent confidence level $(p<.05)$.

\section{E N D N O T E S}

1. Children's Bureau, Administration for Children and Families, "The Adoption and Foster Care Analysis and Reporting System (AFCARS) Report” (Washington, DC: U.S. Department of Health and Human Services, 2010). Available at http://www.acf.hhs.gov/programs/cb/stats_research/afcars/ tar/report17.htm.

2. See N. J. Hochstadt et al., "The Medical and Psychosocial Needs of Children Entering Foster Care," Child Abuse \& Neglect, vol. 1, no. 1 (1987): 53-62, and L. Leslie et al., "Addressing the Developmental and Mental Health Needs of Young Children in Foster Care," Developmental and Behavioral Pediatrics, vol. 26, no. 2, (2005): 140-151.

3. R. Racusin et al., "Psychosocial Treatment of Children in Foster Care: A Review," Community Mental Health Journal, vol. 41, (2005): 199-221.

4. Healthy Foster Care America, "Health Care Standards: Fundamental Principles” (Elk Grove Village, IL: American Academy of Pediatrics, 2010). Available at http://www.aap. org/fostercare/health_care_standard.html.

5. Children's Bureau, Administration for Children and Families, "Child Maltreatment 2009" (Washington, DC: U.S. Department of Health and Human Services, 2010). Available at http://www.acf.hhs.gov/programs/cb/pubs/cm09.
6. Jim Casey Youth Opportunities Initiative, "Youth Aging Out of Foster Care: What Policymakers Need to Know" (St. Louis, MO: Jim Casey Youth Opportunities Initiative, 2010). Available at http://www.jimcaseyyouth.org/youth-aging-outfoster-care-what-policymakers-need-know.

7. Guardian Scholars, "More than a Scholarship" (Fullerton, CA: California State University, 2007). Available at http:// www.fullerton.edu/guardianscholars/scholarship.htm.

8. Children's Defense Fund, "Policy Priorities: Fostering Connections to Success and Increasing Adoptions Act" (Washington, DC: Children's Defense Fund, 2011).

9. "Eligible" refers to foster youths eligible under Title IV-E. Title IV-E eligibility requirements include evidence for the placement, placement with the state or a public agency with which the state has an agreement, eligibility for AFDC, placement in a licensed facility, and verification of facility safety. See Children's Bureau, Administration for Children and Families, "Title IV-E Foster Care Eligibility Review Guide" (Washington, DC: U.S. Department of Health and Human Services, 2006). Available at http://www.acf.hhs.gov/programs/cb/laws_policies/policy/im/2001/im0111a1_2007.htm.

10. Clark M. Peters et al., "Extending Foster Care to Age 21: Weighing the Costs to Government against the Benefits to Youth," Chapin Hall Issue Brief, June (Chicago, IL: Chapin Hall at the University of Chicago, 2009). Available at http:// www.chapinhall.org/sites/default/files/publications/Issue_ Brief\%2006_23_09.pdf.

11. The eleven states that employ this legislation are: Alabama, Arkansas, Illinois, Maryland, Massachusetts, Minnesota, Nebraska, New York, Tennessee, Texas, and West Virginia, as well as the District of Columbia. See Jim Casey Youth Opportunities Initiative, "Foster Care Extended to Age 21" (St. Louis, MO: Jim Casey Youth Opportunities Initiative, 2011). Available at http://www.jimcaseyyouth.org/ foster-care-to-21.

12. Clark M. Peters et al., "Extending Foster Care to Age 21: Weighing the Costs to Government against the Benefits to Youth." Available at http://www.chapinhall.org/sites/default/ files/publications/Issue_Brief\%2006_23_09.pdf.

13. National Data Archive on Child Abuse and Neglect, Datasets, "List of Holdings" (Ithaca, NY: Family Life Development Center, College of Human Ecology, Cornell University, 2011). Available at http://www.ndacan.cornell.edu/ NDACAN/Datasets_List.html. 
A B OUT THE AUTHORS

Wendy A. Walsh is a research assistant professor of sociology at the Crimes against Children Research Center and a research associate at the Carsey Institute at the University of New Hampshire (wendy.walsh@unh.edu).

Beth Mattingly is director of research on vulnerable families at the Carsey Institute and a research assistant professor of sociology at the University of New Hampshire (beth.mattingly@unh.edu).

\section{A C K N O W L E D G M EN T S}

We are grateful for feedback from Jessica Bean at the Carsey Institute; Theodore P. Cross at the University of Illinois at Urbana-Champaign; Melissa Wells at the University of New Hampshire; Barbara Ray at Hiredpen for editorial assistance; and Curt Grimm, Laurel Lloyd Earnshaw, and Amy Sterndale at the Carsey Institute for their comments and suggestions. 


\section{$\triangle$ UNIVERSITY of NEW HAMPSHIRE}

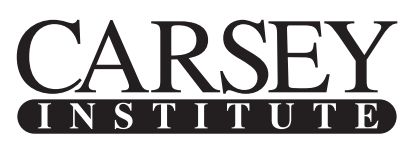

Building knowledge for families and communities

The Carsey Institute conducts policy research on vulnerable children, youth, and families and on sustainable community development. We give policy makers and practitioners timely, independent resources to effect change in their communities.

This work was supported by the Annie E. Casey Foundation, the W. K. Kellogg Foundation, and an anonymous donor.

Huddleston Hall

73 Main Street

Durham, NH 03824

$(603) 862-2821$

www.carseyinstitute.unh.edu 